\title{
LOS CRITERIOS INTERPRETATIVOS DEL CONSEJO DE TRANSPARENCIA. ALCANCE Y SIGNIFICADO
}

Interpretative criteria of the transparency council. Scope and meaning

DOI: http://dx.doi.org/10.15304/dereito.27.Ext.5785

\author{
Daniel Neira Barral \\ Profesor Asociado de Derecho Internacional \\ Universidade de Santiago de Compostela \\ daniel.neira@usc.es
}

\section{Resumen}

El art. recensiona y analiza los criterios interpretativos del Consejo de la Transparencia y Buen Gobierno. La aprobación de la LETAI y las competencias atribuidas en ella al Consejo de la Transparencia obliga a abordar los distintos criterios que esta institución va dictando al objeto de clarificar los problemas que puedan generar las interpretaciones de los preceptos contenidos en la ley. Todo ello para dar cumplimiento a la propia naturaleza de este consejo como órgano de control, de divulgación o informador cuando no clarificador del derecho de acceso a la información y transparencia.

Palabras clave: Transparencia, acceso información, Consejo de la Transparencia y Buen Gobierno, criterios interpretativos.

\section{Abstract}

The art. reviews and analyzes the interpretive criteria of the Council of Transparency and Good Governance. The approval of the LETAI and the competences attributed in it to the Transparency Council obliges to address the different criteria that this institution is dictating in order to clarify the problems that may arise from interpretations of the precepts contained in the law. All this to comply with the very nature of this council as a body of control, disclosure or information when not clarifying the right of access to information and transparency.

Keywords: Transparency, access to information, Council on Transparency and Good Governance, interpretive criteria.

\section{SUMARIO}

1. INTRODUCCIÓN.;- 2. EL CRITERIO CI/001/2015.;-3. APLICACIÓN DE LOS LÍMITES AL DERECHO DE ACCESO A LA INFORMACIÓN.;- 4. ALCANCE DE LAS OBLIGACIONES DE TRANSPARENCIA DE LAS ENTIDADES PRIVADAS.;- 4.1. Aplicación de las obligaciones de publicidad activa.;- 4.2. Alcance de las obligaciones de publicidad activa.;- 5 . PUBLICIDAD ACTIVA DE LOS DATOS DEL DNI Y DE LA FIRMA MANUSCRITA.;- 5.1. Consideración del DNI y de la firma manuscrita como dato de carácter personal.;- 5.2. Aplicación del art. 15 de la LETAI.;- 6. ACTUACIÓN ANTE SOLICITUDES DE INFORMACIÓN COMPLEJA O

Recibido: 10/12/2017. Aceptado: 09/09/2018. 
VOLUMINOSA.;- 7. CAUSAS DE INADMISIÓN DE SOLICITUDES DE INFORMACIÓN: INFORMACIÓN DE CARÁCTER AUXILIAR O DE APOYO.;- 8. ACCIÓN PREVIA DE REELABORACIÓN.;- 9. REGULACIONES ESPECIALES DEL DERECHO DE ACCESO A LA INFORMACIÓN PÚBLICA.;- 10. EL CRITERIO CI/009/2015.;- 11. LA DESESTIMACIÓN DE UNA SOLICITUD DE ACCESO A LA INFORMACIÓN POR SILENCIO.;- 12. CONCLUSIÓN. BIBLIOGRAFÍA.

\section{INTRODUCCIÓN}

El Consejo de Transparencia y Buen Gobierno publica en su página web ${ }^{1}$ criterios interpretativos sobre diversas cuestiones de la LETAI. Y esto es así por lo expuesto en su art. 38.2.a), en el cual se recuerda que corresponde a la Presidenta del Consejo de Transparencia y Buen Gobierno la adopción de criterios de interpretación uniforme de las obligaciones contenidas en la LETAI, atribución reiterada en el art. 8.2.b) del Real Decreto 919/2014, de 31 de octubre, por el que se aprueba el Estatuto de dicho órgano. ${ }^{2}$

Así, quien adopta los criterios de interpretación uniforme de las obligaciones contenidas en la LETAI es el presidente/a del Consejo de Transparencia y Buen Gobierno, aprobando, previo informe de la Comisión de Transparencia y Buen Gobierno ${ }^{3}$, directrices, recomendaciones o guías relativas a su aplicación o interpretación.

Parece existir inicialmente cierta distinción entre unos "criterios de interpretación" que podría aprobar la Presidencia del Consejo de Transparencia y Buen Gobierno sin informe previo de la Comisión de Transparencia y Buen Gobierno, y unas "directrices, recomendaciones o guías relativas a su aplicación o interpretación", cuya aprobación, por el contrario, sí que necesitaría de dicho informe previo. A juicio de Blanes Climent, la importancia práctica que tienen los criterios de interpretación y las directrices, recomendaciones o guías relativas a su aplicación o interpretación, justifica sobradamente el informe previo de la Comisión de Transparencia y Buen Gobierno. Además, el informe previo de la Comisión de Transparencia y Buen Gobierno previsto en el art. 8.2.b) del Estatuto del referido consejo, persigue otra clara finalidad, que las instituciones o

\footnotetext{
${ }^{1}$ En http://www.consejodetransparencia.es/ct_Home/Actividad/criterios.html

2 Este art. 8.2.b) del Real Decreto 919/2014, de 31 de octubre, por el que se aprueba el Estatuto del Consejo de Transparencia y Buen Gobierno, introduce además, un requisito adicional, el informe previo de la Comisión de Transparencia y Buen Gobierno:

"(...) El presidente del Consejo de Transparencia y Buen Gobierno (...) en el desarrollo de sus funciones, es el órgano competente para: (...) b) Adoptar criterios de interpretación uniforme de las obligaciones contenidas en la Ley 19/2013, de 9 de diciembre, en el reglamento que desarrolle dicha ley o en este Estatuto, aprobando, previo informe de la Comisión de Transparencia y Buen Gobierno, directrices, recomendaciones o guías relativas a su aplicación o interpretación".

${ }^{3}$ Recogida en el art. 36 de la LETAI, la Comisión de Transparencia y Buen Gobierno (órgano del Consejo de Transparencia y Buen Gobierno), está compuesta por un representante del Congreso de los Diputados, Senado, Defensor del Pueblo, Tribunal de Cuentas, Agencia Española de Protección de Datos, Secretaría de Estado de Administraciones Públicas y la Autoridad Independiente de Responsabilidad Fiscal.
} 
entidades que van a aplicar esos criterios interpretativos a la hora de cumplir las obligaciones impuestas por la LETAI puedan pronunciarse con carácter previo a su aprobación ${ }^{4}$. Otra cuestión de interés resulta del examen de a quienes se le aplican estos criterios interpretativos, ya que si bien está perfectamente delimitado el ámbito de aplicación subjetivo en la LETAI, se da incluso la paradoja de que instituciones representadas en la Comisión de Transparencia, no están sujetas a los pronunciamientos del Consejo ante una reclamación presentada frente a esa institución (Congreso, Senado, Defensor del Pueblo) sin embargo, frente a otros miembros, sí, léase Agencia Española de Protección de Datos o Secretaría de Estado. Campos Acuña sostiene que sin perjuicio de cuestiones orgánicas, los criterios emitidos, son valiosos por su carácter informador en una materia novedosa y con escaso recorrido doctrinal y jurisprudencial, y que son criterios de interpretación sujetos, en última instancia, a la interpretación que, en ejercicio de la función jurisdiccional, ejerzan jueces y tribunales, así como a una distinta y razonada aplicación de la norma por los sujetos incluidos en su ámbito de aplicación, entre ellos, las entidades locales ${ }^{5}$.

\section{EL CRITERIO CI/001/2015 6}

Este criterio, de 24 de junio de 2015, se refiere al alcance de las obligaciones de los órganos, organismos y entidades del sector público estatal en materia de acceso a la información pública sobre sus relaciones de puestos de trabajo, catálogos, plantillas orgánicas, etc., y las retribuciones de sus empleados o funcionarios.

La Disposición Adicional $5^{a}$ de la LETAI establece que el Consejo de Transparencia y Buen Gobierno y la Agencia Española de Protección de Datos adoptarán conjuntamente los criterios de aplicación, en su ámbito de actuación, de las reglas contenidas en el art. 15 de esta Ley, en particular, en lo que respecta a la ponderación del interés público en el acceso a la información y la garantía de los derechos de los interesados cuyos datos se contuviesen en la misma, de conformidad con lo dispuesto en esta Ley y en la Ley Orgánica 15/1999, de 13 de diciembre. En su virtud, la Presidencia del Consejo y la Dirección de la Agencia Española de Protección de Datos han adoptado criterios interpretativos sobre el alcance de las obligaciones de los órganos, organismos y entidades del sector público estatal ${ }^{7}$ en materia de acceso a la información pública obrante en su poder sobre:

\footnotetext{
${ }^{4}$ En https://miguelangelblanes.com/2015/11/20/los-criterios-interpretativos-de-la-leyestatal-de-transparencia/

5 CAMPOS ACUÑA, C., El Consultor de los Ayuntamientos, num. 24, Sección Zona Local / Observatorio de Transparencia, Quincena del 30 de diciembre de 2015 al 14 de enero de 2016, Ref. 2930/2015, p. 2930.

${ }^{6} \mathrm{CI} / 001 / 2015$ de 24 de junio de 2015: es la referencia de la nomenclatura utilizada para señalar el criterio interpretativo conforme al utilizado por el CTBG.

7 Enunciados en el art. 2 de la LETAI.
} 
1. Relaciones de Puestos de Trabajo, catálogos, plantillas orgánicas, etc.

2. Puesto de trabajo desempeñado por uno o varios de sus empleados o funcionarios.

3. Las retribuciones asignadas a uno o varios puestos de trabajo determinados, con identificación o no de sus perceptores.

4. Las retribuciones vinculadas a la productividad o al rendimiento de sus empleados o funcionarios, con identificación o no de sus perceptores.

En principio y con carácter general, la información referida a la relación de puestos de trabajo, catálogo o plantilla orgánica, con o sin identificación de los empleados o funcionarios públicos ocupantes de los puestos, se consideran datos meramente identificativos relacionados con la organización, funcionamiento o actividad pública del órgano, de modo que, conforme al art. 15, número 2 , de la LETAI, y salvo que en el caso concreto prevalezca la protección de datos personales u otros derechos constitucionalmente protegidos sobre el interés público en la divulgación, se concederá el acceso a la información ${ }^{8}$. Sin embargo, la información no se facilitará cuando el acceso suponga un perjuicio para uno o varios de los bienes enumerados en el art. 14.1 de la LETAI y la limitación sea justificada, proporcionada a su objeto y finalidad de protección ${ }^{9}$ y haya tenido en cuenta las circunstancias del caso concreto, especialmente la concurrencia en el mismo de un interés superior que justifique el acceso. Tampoco se facilitará cuando el acceso afecte a uno o varios empleados o funcionarios públicos que se encuentren en una situación de protección especial. Coincidimos aquí con el criterio asumido por el Consejo de la Transparencia toda vez que entendemos que el empuje ciudadano ante la necesidad de conocer, acceder, participar o controlar los asuntos públicos alimentado por la cascada de leyes autonómicas que engrosan boletines oficiales, se está destapando entre otras como una herramienta para la lucha contra la corrupción, pero no deberían servir para justificar el menoscabo del derecho a la intimidad, el honor, la propia imagen o seguridad, en este caso, del personal al servicio de la administración. Y decimos esto siendo un acérrimo defensor de la transparencia y consciente de que la batalla pugilística (como describe el profesor Cotino) que mantiene el peso pesado de la protección de datos -ley orgánicafrente al peso pluma del derecho de acceso a la información -ley ordinaria- , de momento, parece que se pierde, y aunque mantengamos el empeño en la defensa del débil, esto no puede ser excusa para el "vale todo".

El término clave que viene dibujándose para compensar el citado desequilibrio resulta del ejercicio de ponderación que realizarán los órganos de control. Así pues, si nos acogemos a la ponderación, esta

\footnotetext{
${ }^{8}$ R/0007/2017 CTBG estimando el acceso a la información. Retribuciones de Altos Cargos en 2015.

9 R/0059/2017 CTBG sobre Información parcial. Desglose del concepto "otras retribuciones en especie"
} 
vendrá determinada por el caso concreto y avalada por lo que digan las normas y el mayor interés general, siendo lo lógico volcarse hacia el lado de la transparencia y publicidad cuanto más cerca nos encontremos, por ejemplo, de la toma de decisiones, que es lo que debería interesar al ciudadano.

Las relaciones de puestos de trabajo en la administración, los presupuestos o las partidas de personal, ya venían siendo públicas (otra cosa es el grado de acceso a las mismas), con lo que lo determinante para ejercer el control, facilitar publicidad y conocer o acceder a la información, debería estar íntimamente relacionado y conectado con el "principio de proximidad" para con la toma de decisiones, siendo de interés el nombre y datos personales (léase apellidos, puesto, cargo o retribución) de las personas que estrechen el círculo en esa toma y debiendo importar poco cuanto más lejos y desconectado se encuentre el personal de las mismas ${ }^{10}$.

\section{APLICACIÓn De los Límites AL DERECHO de ACCESO A LA INFORMACIÓN}

Esta cuestión está tratada en el Criterio CI/002/2015. El art. 5.3 de la Ley establece que, en materia de publicidad activa, serán de aplicación "en su caso" los límites al derecho de acceso a la información pública previstos en el art. 14 y, especialmente, el derivado de la protección de datos de carácter personal, regulado en el art. 15.

A este respecto, cuando la información contuviera datos especialmente protegidos, la publicidad sólo se llevará a cabo previa disociación de los mismos $^{11}$. En este sentido, interesante traer a colación resolución del Consejo de Transparencia ${ }^{12}$ en la cual según se desprende de la documentación obrante en el expediente, un ciudadano solicitó información al Ministerio de Hacienda y Administraciones Públicas, con base en la LETAI $^{13}$ en la que, si inicialmente se desestimó la solicitud, el Consejo estimo la reclamación concluyendo la necesidad de aportar la documentación requerida. Respecto al derecho de información, el art. 14 recoge los límites que atienden al equilibrio necesario entre la transparencia y la protección de otros bienes e intereses, públicos o privados, que pueden estar presentes en cada caso concreto. El art.

\footnotetext{
${ }^{10}$ R/0001/2017. Estimada en relación con la identificación y retribuciones anuales de sus trabajadores eventuales (2014-2015) prevalece el Derecho de acceso frente a la protección de datos.

11 R/0059/2017 CTBG sobre Información parcial. Desglose del concepto "otras retribuciones en especie".

${ }_{12}$ Resolución 99/2016 de Reclamación presentada al amparo del art. 24 de la LETAI.

13 La información solicitada fue el número de Abogados del Estado con compatibilidad para actividades privadas en vigor y dentro de éstas los que la tiene otorgada para el ejercicio privado de la abogacía y la relación no nominativa de los Abogados del Estado (igual que la que tiene publicada en el Portal de Transparencia del Gobierno para los funcionarios de la Administración General del Estado, que expresa el puesto que se ocupa, lugar del desempeño, actividad privada declarada compatible) que tiene autorización de compatibilidad para actividades privadas.
} 
establece que el derecho de acceso podrá ser limitado cuando acceder a la información suponga un perjuicio para:

a) La seguridad nacional ${ }^{14}$.

b) La defensa.

c) Las relaciones exteriores ${ }^{15}$.

d) La seguridad pública.

e) La prevención, investigación y sanción de los ilícitos penales, administrativos o disciplinarios ${ }^{16}$.

f) La igualdad de las partes en los procesos judiciales y la tutela judicial efectiva.

g) Las funciones de administrativas de vigilancia, inspección y control ${ }^{17}$.

h) Los intereses económicos y comerciales ${ }^{18}$.

i) La política económica y monetaria ${ }^{19}$.

j) El secreto profesional y la propiedad intelectual e industrial ${ }^{20}$.

k) La garantía de la confidencialidad o el secreto requerido en procesos de toma de decisión.

I) La protección del medio ambiente.

El art. 15 establece el sistema de protección de datos de carácter personal y señala que si la información solicitada contuviera datos especialmente protegidos a los que se refiere el apartado 2 del art. 7 de la Ley Orgánica 15/1999, de 13 de diciembre, de Protección de Datos de Carácter Personal, el acceso únicamente se podrá autorizar en caso de que se

${ }^{14}$ R/0219/2016. Art. 14 d) Seguridad pública. Información parcial. Estimada por motivos formales. Número de vigilantes con armas y relación de empresas de seguridad por Centro Penitenciario.

${ }^{15}$ R/0235/2016. Art. 14.1 c) Relaciones exteriores. Datos estadísticos extranjería.

${ }^{16} \mathrm{R} / 0188 / 2016$. Art. 14.1 e) ilícitos penales o administrativos. Desestimada. Copia de la denuncia presentada por España contra Gibraltar ante la Comisión Europea en el año 2012. Ministerio de Asuntos Exteriores y Cooperación.

$17 \mathrm{R} / 0062 / 2016$. Art. $14.1 \mathrm{~g}$ ) funciones de vigilancia y control. Desestimada. Acceso como interesado a expediente en curso sobre comercialización del producto "ala octa".

$\mathrm{R} / 0507 / 2016$. Art. $14.1 \mathrm{~g}$ ) funciones de vigilancia y control. Inadmitida. Denuncias interpuestas por un Agente Medioambiental en Corporación de Derecho Público/Confederación Hidrográfica del Júcar.

R/0508/2016. Art. $14.1 \mathrm{~g})$ funciones de vigilancia y control. Inadmitida. Denuncias interpuestas por un Agente Medioambiental. Corporación de Derecho Público/Confederación Hidrográfica del Júcar.

$18 \mathrm{R} / 0376 / 2016$. Art. $14.1 \mathrm{~h}$ ) intereses económicos y comerciales. Desestimada. Uso de la infraestructura viaria de RENFE para el transporte de mercancías por parte de empresas privadas. Entidad Pública Empresarial/RENFE.

R/0378/2016. Art. $14.1 \mathrm{~h}$ ) intereses económicos y comerciales. Estimada por motivos formales. Número de viajeros transportados a diario en trenes de Larga Distancia.

$\mathrm{R} / 0511 / 2016$. Art. $14.1 \mathrm{~h}$ ) intereses económicos y comerciales. Desestimada. Ingresos y beneficios de todos los aeropuertos de AENA.

${ }_{19}$ R/0105/2015. Art. 14.1 h) intereses económicos y comerciales. Estimada. Costes de los canales públicos de televisión.

${ }^{20} \mathrm{R} / 0275 / 2016$. Art. $14.1 \mathrm{j}$ ) El secreto profesional y la propiedad intelectual e industrial. Archivada. Acceso al Código Fuente de la aplicación LEXNET-MINISTERIO DE JUSTICIA. 
contase con el consentimiento expreso y por escrito del afectado, a menos que dicho afectado hubiese hecho manifiestamente públicos los datos con anterioridad a que se solicitase el acceso.

Además, si la información incluyese datos especialmente protegidos a los que se refiere el apartado 3 del art. 7 de la Ley Orgánica 15/1999, de 13 de diciembre, o datos relativos a la comisión de infracciones penales 0 administrativas que no conllevasen la amonestación pública al infractor, el acceso sólo se podrá autorizar en caso de que se cuente con el consentimiento expreso del afectado o si aquél estuviera amparado por una norma con rango de Ley ${ }^{21}$.

Con carácter general, y salvo que en el caso concreto prevalezca la protección de datos personales u otros derechos constitucionalmente protegidos sobre el interés público en la divulgación que lo impida, se concederá el acceso a información que contenga datos meramente identificativos relacionados con la organización, funcionamiento o actividad pública del órgano. Cuando la información solicitada no contuviera datos especialmente protegidos, el órgano al que se dirija la solicitud concederá el acceso previa ponderación suficientemente razonada del interés público en la divulgación de la información y los derechos de los afectados cuyos datos aparezcan en la información solicitada, en particular su derecho fundamental a la protección de datos de carácter personal.

Para la realización de la citada ponderación ${ }^{22}$, dicho órgano tomará particularmente en consideración los siguientes criterios:

a) El menor perjuicio a los afectados derivado del transcurso de los plazos establecidos en el art. 57 de la Ley 16/1985, de 25 de junio, del Patrimonio Histórico Español.

b) La justificación por los solicitantes de su petición en el ejercicio de un derecho o el hecho de que tengan la condición de investigadores y motiven el acceso en fines históricos, científicos o estadísticos.

c) El menor perjuicio de los derechos de los afectados en caso de que los documentos únicamente contuviesen datos de carácter meramente identificativo de aquéllos.

d) La mayor garantía de los derechos de los afectados en caso de que los datos contenidos en el documento puedan afectar a su intimidad o a su seguridad, o se refieran a menores de edad.

\footnotetext{
${ }^{21}$ Destacable en el ámbito del consentimiento expreso como el Reglamento Europeo de Protección de datos 679/2016 extiende la condición de expreso para validar el consentimiento como base legal de un tratamiento de datos personales.

${ }^{22}$ R/0105/2015. Art. $14.1 \mathrm{~h}$ ) intereses económicos y comerciales" Estimada. Costes de los canales públicos de televisión.

R/0154/2017. Información parcial estimada. Nivel de ejecución del Capítulo I - Gastos de Personal. La Administración debe dar la información. Tesorería General de la Seguridad Social (TGSS)
} 
No será aplicable lo establecido en los apartados anteriores si el acceso se efectúa previa disociación de los datos de carácter personal de modo que se impida la identificación de las personas afectadas. La normativa de protección de datos personales será de aplicación al tratamiento posterior de los obtenidos a través del ejercicio del derecho de acceso.

Los arts. 14 y 15 de la LETAI establecen los límites del derecho de acceso a la información pública que, de conformidad con el art. 5.3 resultan también aplicables a las obligaciones de publicidad activa regulados en la norma. El proceso de aplicación de estas normas comprende las siguientes etapas o fases sucesivas:

I. Valorar si la información solicitada o sometida a publicidad activa contiene o no datos de carácter personal, entendiéndose por éstos los definidos en el art. 3 de la Ley Orgánica 15/1999, de 13 de diciembre, de Protección de Datos de Carácter Personal.

II. En caso afirmativo, valorar si los datos son o no datos especialmente protegidos en los términos del art. 7 de la Ley Orgánica 15/1999, esto es: a) datos reveladores de la ideología, afiliación sindical, religión y creencias; b) datos de carácter personal que hagan referencia al origen racial, a la salud y a la vida sexual, y c) datos de carácter personal relativos a la comisión de infracciones penales o administrativas.

Si contuviera datos de carácter personal especialmente protegidos, la información solo se podrá publicar o facilitar en el supuesto de los datos de la letra a) anterior, cuando se cuente con el consentimiento expreso y por escrito del afectado, a menos que dicho afectado hubiese hecho manifiestamente públicos los datos con anterioridad a que se solicitase el acceso. En el supuesto de los datos de la letra b) anterior, cuando se cuente con el consentimiento expreso del afectado o estuviera amparado por una norma con rango de ley y en el supuesto de los datos de la letra c) anterior, y siempre que las correspondientes infracciones penales o administrativas no conlleven la amonestación pública al infractor, cuando se cuente con el consentimiento expreso del afectado o estuviera amparado por una norma con rango de Ley.

III. Si los datos de carácter personal contenidos en la información no fueran datos especialmente protegidos, valorar si son o no exclusivamente datos meramente identificativos relacionados con la organización, el funcionamiento 0 la actividad pública del órgano 0 entidad correspondiente.

Si los datos contendidos son exclusivamente identificativos relacionados con la organización, el funcionamiento o la actividad pública del órgano o entidad, la información se publicará o facilitará con carácter general, salvo que en el caso concreto prevalezca la protección de datos personales y otros derechos constitucionalmente protegidos sobre el interés público en la divulgación. 
IV. Si los datos de carácter personal no fueran meramente identificativos y relacionados con la organización, el funcionamiento o la actividad pública del órgano o no lo fueran exclusivamente, efectuar la ponderación prevista en el art. 15.3 de la LETAI.

V. Finalmente, una vez realizados los pasos anteriores, valorar si resultan de aplicación los límites previstos en el art. 14.

Los límites a que se refiere el art. 14 de la LETAI, a diferencia de los relativos a la protección de los datos de carácter personal, no se aplican directamente, sino que de acuerdo con la literalidad del texto del número 1 del mismo, "podrán" ser aplicados. De esta manera, los límites no operan "ni automáticamente a favor de la denegación ni absolutamente en relación a los contenidos" ${ }^{23}$.

La invocación de motivos de interés público para limitar el acceso a la información deberá estar ligada con la protección concreta de un interés racional y legítimo. En este sentido su aplicación no será en ningún caso automática, antes al contrario, deberá analizarse si la estimación de la petición de información supone un perjuicio (test del daño) concreto, definido y evaluable. Este, además no podrá afectar o ser relevante para un determinado ámbito material, porque de lo contrario se estaría excluyendo un bloque completo de información. Del mismo modo, es necesaria una aplicación justificada y proporcional atendiendo a la circunstancia del caso concreto y siempre que no exista un interés que justifique la publicidad o el acceso (test del interés público).

Así, el Consejo de Transparencia y Buen Gobierno y la Agencia Española de Protección de Datos proceden concluir que los arts. 14 y 15 de la LETAI regulan los límites del derecho de acceso a la información que no operan de forma automática, sino que habrán de ser aplicados de acuerdo con las reglas de aplicación y los elementos de ponderación que establecen la citada Ley y la LOPD. Además, el orden de ponderación opera desde el art. 15 al 14 con valoración de los elementos que modulan la toma de decisiones. El art. 14 no supondrá, en ningún caso una exclusión automática del derecho a la información, antes al contrario deberá justificar el test del daño y el del interés público para ser aplicado. Del mismo modo, su aplicación deberá justificar y motivar la denegación ${ }^{24}$.

En cualquier caso si no cupiera el otorgamiento del acceso a la totalidad de la información una vez hechas las valoraciones anunciadas, se concederá acceso parcial previa omisión de la información afectada por el límite salvo que de ello resulte una información distorsionada o que carezca de sentido. En este caso, deberá indicarse al solicitante que parte de la información ha sido omitida. Todas las resoluciones denegatorias, total o parcialmente, del acceso en aplicación de los límites previstos en el

\footnotetext{
${ }^{23}$ Criterio CI/002/2015 de 24 de junio de 2015.

$24 \mathrm{R} / 0076 / 2016$. Falta concretar la información. Inadmitida. Acceso a los expedientes de la Presa de Santa Cruz de Pinares: sanciones, informes técnicos, etc.
} 
art. 14 de la LETAI serán objeto de publicidad en los términos establecidos en el art. 14.3 de la misma.

\section{ALCANCE DE LAS OBLIGACIONES DE TRANSPARENCIA DE LAS ENTIDADES PRIVADAS}

Este asunto está tratado en el Criterio CI/003/2015. Las cuestiones planteadas, referidas a las obligaciones de publicidad activa aplicables a las entidades sin ánimo de lucro que superan los límites de financiación pública señalados en la LETAI, han sido objeto de respuesta por parte del CTBG que cree oportuno formular un criterio interpretativo a fin de obviar interpretaciones que no se ajusten a lo que establece la norma aplicable. Las consultas relativas a las entidades del art. 3 de la mencionada ley afectan a los partidos políticos, organizaciones sindicales y organizaciones empresariales. Así, las entidades privadas que perciban durante un año ayudas o subvenciones públicas por importe superior a 100.000 euros o cuando al menos el $40 \%$ del total de sus ingresos anuales tengan el carácter de ayuda o subvención pública siempre que alcance, como mínimo, los 5.000 euros.

\subsection{Aplicación de las obligaciones de publicidad activa}

En cuanto al alcance de las obligaciones, la propia norma establece que las entidades sujetas a la misma en su condición de ayudas o subvenciones públicas solo lo serán en relación a lo dispuesto en el Capítulo II del Título I de la LETAI, es decir, a las obligaciones de transparencia o publicidad activa.

Estas obligaciones están recogidas en los arts. 5 a 8 de la LETAI, preceptos en los que se desarrollan, además de los principios generales, el alcance de la publicidad requerida en función del tipo de información y de los sujetos obligados. Según el art. 3 LETAI, las entidades privadas sólo están sujetas a las obligaciones de publicidad activa, no al derecho de acceso a la información; es decir, están obligadas a publicar la información que recoge la ley, pero no a tramitar solicitudes de información realizadas por los ciudadanos.

\subsection{Alcance de las obligaciones de publicidad activa}

Como ya se ha adelantado, las obligaciones de publicidad activa están recogidas en los arts. 5 a 8, por consiguiente, tanto los partidos políticos, organizaciones sindicales y empresariales como las entidades que reciban subvenciones dentro de los umbrales previstos por el art. 3 de la LETAI antes mencionados, estarán obligados a cumplir:

- Los principios generales enunciados en el art. 5 a excepción hecha de su apartado primero.

- $\quad$ El apartado primero del art. 6 en lo relativo a información sobre su estructura, organización y funciones. 
- $\quad$ El art. 8 en su totalidad, y ello por cuanto su apartado primero se refiere en general a todos los sujetos incluidos en el ámbito de aplicación de la norma.

Sin perjuicio de lo anterior, el apartado 2 del art. 8 LETAI contiene unas matizaciones que son de aplicación a los contratos, convenios y subvenciones de carácter privado. En este sentido, deberán publicarse sólo los contratos y convenios cuando se celebren con una Administración Pública así como las subvenciones cuando el órgano concedente sea una Administración Pública, no afectando a las actuaciones privadas de los mencionados sujetos obligados.

\section{PUBLICIDAD ACTIVA DE LOS DATOS DEL DNI Y DE LA FIRMA MANUSCRITA}

La referencia para este tema es el Criterio CI/004/2015. La LETAI establece en sus arts. 6 a 8 una serie de obligaciones de transparencia a la que están sujetas las entidades y organismos incluidos en el ámbito de aplicación de la norma. ${ }^{25}$ La misma norma, en su art. 15 , regula la articulación de la relación entre, por un lado, la protección de los datos de carácter personal que pudiera contener la información y, por otro, el derecho a la transparencia y a la información que la LETAI ampara. A tal respecto, dispone que si la información solicitada contuviera datos especialmente protegidos a los que se refiere el apartado 2 del art. 7 de la Ley Orgánica 15/1999, de 13 de diciembre, de Protección de Datos de Carácter Personal, el acceso únicamente se podrá autorizar en caso de que se contase con el consentimiento expreso y por escrito del afectado, a menos que dicho afectado hubiese hecho manifiestamente públicos los datos con anterioridad a que se solicitase el acceso. Si la información incluyese datos especialmente protegidos a los que se refiere el apartado 3 del art. 7 de la citada Ley Orgánica 15/1999, o datos relativos a la comisión de infracciones penales o administrativas que no conllevasen la amonestación pública al infractor, el acceso sólo se podrá autorizar en caso de que se cuente con el consentimiento expreso del afectado o si aquél estuviera amparado por una norma con rango de Ley. Con carácter

${ }^{25}$ En concreto el art. 8.1, letras a) y b) prevé la obligación de publicar:

a) Todos los contratos, con indicación del objeto, duración, el importe de licitación y de adjudicación, el procedimiento utilizado para su celebración, los instrumentos a través de los que, en su caso, se ha publicitado, el número de licitadores participantes en el procedimiento y la identidad del adjudicatario, así como las modificaciones del contrato. Igualmente serán objeto de publicación las decisiones de desistimiento y renuncia de los contratos. La publicación de la información relativa a los contratos menores podrá realizarse trimestralmente.

b) La relación de los convenios suscritos, con mención de las partes firmantes, su objeto, plazo de duración, modificaciones realizadas, obligados a la realización de las prestaciones y, en su caso, las obligaciones económicas convenidas. Igualmente, se publicarán las encomiendas de gestión que se firmen, con indicación de su objeto, presupuesto, duración, obligaciones económicas y las subcontrataciones que se realicen con mención de los adjudicatarios, procedimiento seguido para la adjudicación e importe de la misma. 
general, y salvo que en el caso concreto prevalezca la protección de datos personales u otros derechos constitucionalmente protegidos sobre el interés público en la divulgación que lo impida, se concederá el acceso a información que contenga datos meramente identificativos relacionados con la organización, funcionamiento o actividad pública del órgano ${ }^{26}$.

\subsection{Consideración del DNI y de la firma manuscrita como dato de carácter personal}

Cabe comenzar señalando que, tanto la Ley Orgánica 15/1999, de 13 de diciembre, de protección de datos de carácter personal, como su reglamento de desarrollo son de aplicación a los datos relativos a personas físicas, no jurídicas. Es importante hacer esta precisión sobre todo cuando se esté ante el caso del adjudicatario de un contrato o del firmante de un convenio persona física.

El art. 3 de esta Ley Orgánica 15/1999 define dato de carácter personal como "cualquier información concerniente a personas físicas identificadas o identificables"27. Posteriormente, el Real Decreto 1720/2007, de 21 de diciembre, por el que se aprueba su Reglamento de desarrollo, en su art. $5.1 \mathrm{f}$ ) aclara la cuestión al disponer que dato personal es "cualquier información numérica, alfabética, gráfica, fotográfica, acústica o de cualquier otro tipo concerniente a personas físicas identificadas o identificables". Por lo tanto, procede concluir que los DNI de los firmantes de un convenio o de un contrato tienen la consideración de dato de carácter personal y, por lo tanto, a su publicidad les sería de aplicación las reglas de ponderación del art. 15 de la LETAI.

En lo que respecta a la firma manuscrita, y teniendo en cuenta lo mencionado anteriormente, debe concluirse que nos encontramos ante una información o dato-información gráfica en los términos del Real Decreto $1720 / 2007-y$, por otro, que es concerniente y permite identificar a una persona, toda vez que un convenio o un contrato ya contiene la identidad de los firmantes. Teniendo esto en cuenta, cabe concluir que también la firma manuscrita entraría dentro del concepto de dato de carácter personal.

\subsection{Aplicación del art. 15 de la LETAI}

A continuación, procede considerar las reglas del art. 15 de la LETAI antes mencionado a los efectos de analizar la ponderación entre el derecho a la protección de datos personales y el derecho a la información pública ${ }^{\mathbf{2 8}}$.El apartado 1 del art. 15 viene referido a los datos considerados como "especialmente protegidos" en virtud del art. 7, apartados 2 y 3 de la ley orgánica de protección de datos, es decir, datos que revelen la ideología,

\footnotetext{
${ }^{26}$ Art. 7 de la Ley Orgánica 15/1999, de 13 de diciembre

27 En atención a esta definición, la propia Audiencia Nacional, en el fundamento jurídico segundo de su sentencia de 27 de octubre de 2004 (SAN 6687/2004), afirmó claramente que "el número del DNI es un dato de carácter personal, y por tanto protegido por la ley".

${ }^{28} \mathrm{R} / 0088 / 2016$. Protección de Datos y Art. $14.1 \mathrm{~h}$ ) intereses económicos y comerciales. Estimada. Solicitud copia del contrato entre RTVE y Vídeo Mercury Films.
} 
afiliación sindical, religión y creencias o que hagan referencia al origen racial, a la salud y a la vida sexual. En atención a esta definición, cabe concluir que ni el DNI ni la firma manuscrita tienen la consideración de dato especialmente protegido.

El apartado 2 del art. 15 se refiere a datos meramente identificativos relacionados con la organización, funcionamiento o actividad pública del órgano. Si bien no existe una definición clara de qué datos tendrían esta consideración, podría defenderse la interpretación de que se trataría del nombre, apellidos, dirección o teléfono ${ }^{29}$. Según esto, tampoco el DNI o la firma manuscrita tendrían la consideración de dato meramente identificativo. Sería, pues, la regla recogida en el apartado 3 del art. 15ponderación entre el interés público en la divulgación de la información y los derechos de los afectados- la que se tomó para la consideración del criterio.

Como ya se ha mencionado, el art. 8.1 letras a) y b) prevén, por un lado, la publicación de la identidad del adjudicatario de un contrato y, por otro, los convenios con mención de las partes firmantes. Cabría, por lo tanto, considerar que la publicación del nombre, apellidos y cargo de los firmantes cumpliría con la obligación contenida en dicho precepto. No obstante, y toda vez que las obligaciones de publicidad podrían considerarse como un mínimo y que pudiera ser decisión de un organismo ya sea publicar más información o ya conceder el acceso a la misma en el marco de una solicitud de acceso a la información, sería también conveniente analizar la incidencia que tendría en el titular de los datosDNI y firma manuscrita- la publicación de éstos. Y, para ello, debe ponderarse, como ya se ha dijo, por un lado el interés público en la divulgación de la información y, por otro, la protección de los titulares de los datos. En atención a lo analizado anteriormente, se concluyó lo siguiente:

a. Los organismos y entidades incluidas en el ámbito de aplicación de la Ley deben publicar la identidad de los adjudicatarios de los contratos que suscriban y los convenios con mención a las partes firmantes.

b. Tanto el número de DNI como la firma manuscrita tienen la consideración de dato de carácter personal y, por lo tanto, sería de aplicación lo dispuesto en el art. 15 de la Ley 19/2013, de 9 de diciembre. c. Al no tratarse de datos especialmente protegidos ni tener la consideración de meramente identificativos, su publicidad debe ponderarse en atención al interés público que hubiera en su divulgación y a los derechos de los titulares de los datos.

d.

${ }^{29}$ Tal interpretación sería respaldada por el art. 2.2 del Reglamento de desarrollo de la LOPD que, al excluir su aplicación a determinados ficheros que recojan datos de trabajadores de personas jurídicas, menciona expresamente "nombre y apellidos, las funciones o puestos desempeñados, así como la dirección postal o electrónica, teléfono y número de fax profesionales." 


\section{ACTUACIÓN ANTE SOLICITUDES DE INFORMACIÓN COMPLEJA O VOLUMINOSA}

A esta cuestión se refiere el Criterio CI/005/2015. La necesidad de aprobar el presente criterio vino motivado por la constatación de que, en gran parte de los casos, dichas solicitudes no obtuvieron respuesta en el plazo de un mes previsto en el art. 20.1 de la LETAI, por sus características en concreto por la complejidad o gran volumen de la información solicitada, razón por la cual, el interesado entendió denegada su solicitud, presentando, en consecuencia, la correspondiente reclamación ante el Consejo de Transparencia de acuerdo con lo dispuesto en el art. 24 de la Ley ${ }^{30}$.

La consecuencia relevante de considerar que, una vez transcurrido el plazo previsto para ello, la solicitud se entiende denegada (silencio administrativo con sentido negativo) es que, el procedimiento se entiende finalizado y queda abierta la posibilidad de que los interesados interpongan los recursos que procedan en defensa de sus intereses. Así pues, el efecto de su aplicación es fundamental para el ejercicio de los derechos de los interesados. Así, la Administración puede proceder de oficio a la ampliación de plazos ${ }^{31}$, pero las circunstancias que deben darse para poder hacer uso de esta habilitación legal de ampliación del plazo para resolver una solicitud de acceso que la ley habilita se circunscribe a que el volumen o la complejidad de la información que se solicita lo haga necesario.

La ley se ciñe a estos dos supuestos, el volumen de datos o informaciones y la complejidad de obtener o extraer los mismos. En todo caso, y por tratarse de una excepción al plazo general, deberá ser convenientemente justificada y relacionada con el caso concreto y esta justificación habrá de constar de forma motivada. En consecuencia, de no haber sido notificada con carácter previo a la finalización del plazo de un mes la decisión de la Administración de ampliar dicho plazo en base al art. 20.1, párrafo segundo, se entenderá desestimada la solicitud sin perjuicio de que la Administración pueda remitir posteriormente la información solicitada, con lo que se concluye que la LETAI establece en su art. 20.1, párrafo primero, el plazo general de un mes para resolver las solicitudes de acceso a la información que formulen los interesados, plazo cuyo cómputo comienza a contar a partir de su recepción en el órgano competente para resolver.

\footnotetext{
${ }^{30}$ El art. 20 establece:
}

(...) solicitante y a los terceros afectados que así lo hayan solicitado en el plazo máximo de un mes desde la recepción de la solicitud por el órgano competente para resolver. Este plazo podrá ampliarse por otro mes en el caso de que el volumen o la complejidad de la información que se solicita así lo hagan necesario y previa notificación al solicitante."

Por su parte, el apartado 4 del mismo artículo dispone que: (...) "Transcurrido el plazo máximo para resolver sin que se haya dictado y notificado resolución expresa se entenderá que la solicitud ha sido desestimada."

${ }^{31}$ El art. 20.1, párrafo segundo de la Ley 19/2013, prevé la posible extensión del plazo de resolución de un mes, por otro mes en el caso de que el volumen o la complejidad de la información que se solicita lo haga necesario y previa notificación al solicitante. 
El mismo art. 20.1 señala en su párrafo segundo que dicho plazo podrá ampliarse por otro mes en el caso de que la complejidad o el volumen de la información que se solicita así lo haga necesario. La ampliación del plazo, en caso de que la Administración actuante lo estime necesario, se realizará previa notificación al interesado.

La mencionada notificación a los interesados se deberá realizar antes de que expire el plazo general de un mes que señala la ley. La excepción de ampliación del plazo, además de notificada con carácter previo habrá de ser motivada, con expresión de las circunstancias concretas que justifiquen la ampliación del plazo general, sus causas materiales y sus elementos jurídicos.

\section{CAUSAS DE INADMISIÓN DE SOLICITUDES DE INFORMACIÓN: INFORMACIÓN DE CARÁCTER AUXILIAR O DE APOYO}

Objeto de estas causas de inadmisión es el Criterio CI/006/2015. El art. 18.1.b) de la LETAI establece como causa de inadmisión de las solicitudes de acceso a la información pública, entre otros supuestos, aquellas referidas a información que tenga carácter auxiliar o de apoyo como la contenida en notas, borradores, opiniones, resúmenes, comunicaciones e informes internos o entre órganos o entidades administrativas.

En primer lugar, es preciso señalar que la redacción del art. 18 de la LETAI establece una serie de causas que permiten declarar la inadmisión de una solicitud de información que, al tener como consecuencia inmediata la finalización del procedimiento, habrán de operar, en todo caso, mediante resolución motivada. Por tanto, será requisito que la resolución por la que se inadmita la solicitud especifique las causas que la motivan y la justificación, legal o material aplicable al caso concreto.

Teniendo en cuenta la redacción del art. 18.1.b), cabe concluir que es la condición de información auxiliar o de apoyo la que permitirá, de forma motivada y concreta invocar un aplicación de la causa de exclusión, siendo la enumeración referida a "notas, borradores, opiniones, resúmenes, comunicaciones e informes internos o entre órganos administrativos" una mera ejemplificación que, en ningún caso, afecta a todos los conceptos enumerados sino a aquellos que tenga la condición principal de auxiliar o de apoyo.

Así pues, es el carácter auxiliar o de apoyo de este tipo de información y no el hecho de que se denomine como una nota, borrador, resumen o informe interno lo que conlleva la posibilidad de aplicar la causa de inadmisión prevista en el art. 18.1.b), de la LETAI. El Consejo de Transparencia entiende que una solicitud de información auxiliar o de apoyo, como la contenida en notas, borradores, opiniones, resúmenes, comunicaciones e informes internos 0 entre órganos 0 entidades administrativas, podrá ser declarada inadmitida ${ }^{32}$ a trámite cuando se den, entre otras, alguna de las siguientes circunstancias:

${ }^{32}$ R/0001/2016. Art. 18.1 b) auxiliar o de apoyo. Inadmitida. Acceso a expedientes de denuncia. 
1. Cuando contenga opiniones o valoraciones personales del autor que no manifiesten la posición de un órgano o entidad.

2. Cuando lo solicitado sea un texto preliminar o borrador sin la consideración de final.

3. Cuando se trate de información preparatoria de la actividad del órgano o entidad que recibe la solicitud.

4. Cuando la solicitud se refiera a comunicaciones internas que no constituyan trámites del procedimiento.

5. Cuando se trate de informes no preceptivos y que no sean incorporados como motivación de una decisión final.

El desglose que incluye el apartado 18.1.b), en notas, borradores, opiniones, resúmenes, comunicaciones e informes internos 0 entre órganos o entidades administrativas, no es una definición nominal sino un ejemplo de documentos que, con un determinado formato, puede contener información que cumpla los condicionantes para poder ser calificada como de carácter auxiliar o de apoyo.

\section{ACCIÓN PREVIA DE REELABORACIÓN}

En este punto hay que referirse al Criterio CI/007/2015. Aclara el Consejo de Transparencia ${ }^{33}$ que por reelaboración ${ }^{34}$ debe entenderse según define la Real Academia de la Lengua: "volver a elaborar algo". Es esta circunstancia la que es exigible para entender que estamos ante un supuesto de reelaboración. El concepto de reelaboración como causa de inadmisión ha sido interpretado por el Consejo de Transparencia y Buen Gobierno en diversas resoluciones de tal manera que puede entenderse aplicable cuando la información que se solicita, perteneciendo al ámbito funcional de actuación del organismo o entidad que recibe la solicitud, deba: a) elaborarse expresamente para dar una respuesta, haciendo uso de diversas fuentes de información, $o$ b) cuando dicho organismo o entidad carezca de los medios técnicos que sean necesarios para extraer y explotar la información concreta que se solicita, resultando imposible proporcionar la información solicitada.

R/0443/2016. Art. 18.1 b) auxiliar o de apoyo. Estimada. Solicitud de Informe a Patrimonio Nacional presentado en juicio de memoria histórica.

R/0023/2017. Art. 18.1 b) información auxiliar o de apoyo. Estimada. Texto del Código de Buenas Prácticas en materia de cláusulas suelo. Información jurídica. No se aplica Art. 18.1 b) auxiliar o de apoyo.

R/0491/2015. Art. 18.1 b) información auxiliar o de apoyo . Estimada. Reuniones y asistentes del Ministro de Industria relacionadas con la elaboración del real decreto de suministro de energía eléctrica.

R/0493/2015. Art. 18.1 b) información auxiliar o de apoyo. Inadmitida. Acceso a informes Ministerio de Hacienda y Administraciones Públicas.

${ }^{33}$ Criterio $\mathrm{CI} / 007 / 2015$.

${ }^{34}$ El art. 18.1.c) de la LETAI establece que se inadmitirán a trámite, mediante resolución motivada, las solicitudes:

c) Relativas a información para cuya divulgación sea necesaria una acción previa de reelaboración. 
Así pues no supondría una causa de inadmisión la solicitud de "información voluminosa", que aparece recogida en el art. 20.1. En este caso, se trata de información cuyo "volumen o complejidad" hace necesario un proceso específico de trabajo o de manipulación para suministrarla al solicitante. En este caso no se estaría ante un supuesto de reelaboración, por lo que tampoco sería un caso de inadmisión de la solicitud sino de ampliación del plazo para resolver ${ }^{35}$.

Igualmente, si la información que, por contener datos de carácter personal, debe ser "anonimizada" o disociada antes de ser suministrada al interesado o bien que, por afectar a alguno de los límites previstos en la norma, el acceso sólo deba proporcionarse respecto de parte de la información, en estos casos, y pese a suponer, implícitamente, un proceso específico de trabajo para proporcionar la información, ninguno de estos dos supuestos puede entenderse como reelaboración. Puede ocurrir también que la información se encuentre en poder de varias unidades informantes que resultan responsables de su custodia pero su autor esté claramente definido. En este caso tampoco se trataría de un caso de reelaboración, operando el art. 19.4 de la LETAI $^{36}$.

Sí sería aplicable el concepto de reelaboración en aquellos supuestos en los que la Administración, teniendo solamente la información en un determinado formato, ésta no sea reutilizable en los términos que señale la Ley, debiendo en este caso ofrecerse la información en los formatos existentes. $^{37}$ En este sentido, la LETAI establece en su art. 5.4 que la Administración debe establecer "los mecanismos adecuados para facilitar la accesibilidad, la interoperabilidad, la calidad y la reutilización de la información publicada". Esta recomendación que supone una buena

${ }^{35}$ En este sentido ya se pronuncia el art. 20.1, párrafo 2 que dice textualmente "Este plazo ( 1 mes) podrá ampliarse por otro mes en el caso de que el volumen o la complejidad de la información que se solicita así lo hagan necesario y previa notificación al solicitante".

${ }^{36}$ El art. 19.4 de la LETAI que establece que cuando la información objeto de la solicitud, aun obrando en poder del sujeto al que se dirige, haya sido elaborada o generada en su integridad o parte principal por otro, se le remitirá la solicitud a éste para que decida sobre el acceso.

37 R/0032/2016. Art. 18.1 c) reelaboración. Desestimada. Programa de intercambio de jeringuillas en centros penitenciarios.

R/0079/2016. Art. 18.1 c) reelaboración. Desestimada. Relación de actividades de Ingeniería de Telecomunicaciones e Industrial reguladas en España.

$\mathrm{R} / 0086 / 2016$. Art. $18.1 \mathrm{c})$ reelaboración. Desestimada. Documentos relativos al "TAX RULING". Ministerio de Hacienda y Administraciones Públicas.

R/0092/2016. Art. 18.1 c) reelaboración. Desestimada. Traslado de mujeres reclusas a módulos de mujeres en toda España.

R/0216/2016. Art. 18.1 c) reelaboración. Estimada. Relación de puestos amortizados de funcionarios (2010-2016).

R/0413/2015. Art. 18.1 c) reelaboración. Desestimada. Acceso a expedientes de subastas y adjudicaciones directas en Madrid.

R/0105/2015. Art. 18.1 c) reelaboración y Art. 14.1 h) intereses económicos y comerciales. Estimada. Costes de los canales públicos de televisión.

R/0026/2017. Art. 18.1 c) reelaboración. Estimada. Número de viajeros en los trenes de cercanías de Madrid desde 2015. 
práctica y que opera desde la entrada en vigor de la ley, puede relacionarse con la situación actual de los documentos e informaciones archivadas que, en muchos casos fueron objeto de elaboración y archivo en formatos PDF y similares. La petición de un formato concreto distinto al existente podría entenderse como reelaboración, cuando dicho formato no esté en poder de la Administración informante, en todo caso la extracción de la información en Excel o Word no entrarían en el supuesto de reelaboración.

En este sentido, es de interés en este punto la R0105/2015 Consejo Transparencia en relación con la solicitud de acceso a la información de los costes de los canales públicos de televisión; así, tras recibir la respuesta negativa de RTVE, el ciudadano presentó reclamación ante el Consejo de Transparencia y Buen Gobierno el 20 de abril de 2015, que la estimó e instó a RTVE a facilitar la información solicitada en el plazo de 15 días. En concreto, el Consejo de Transparencia y Buen Gobierno consideró que no se justificaba adecuadamente que la información tuviera que reelaborarse previamente para proporcionarla y que el conocimiento de la información solicitada no perjudica a los intereses económicos y comerciales de RTVE. En concreto, el Consejo afirmaba en su resolución que "se trata solamente de indicar a la reclamante cuánto invierte RTVE en cada canal de televisión en un año (el montante total en euros, sin desglosar las partidas especificas), sin incidir en las causas por las que destina más o menos recursos a un determinado canal en detrimento de los demás o sobre si sería conveniente invertir más recursos a un canal que a otro"${ }^{\prime 38}$.

\section{REGULACIONES ESPECIALES DEL DERECHO DE ACCESO A LA INFORMACIÓN PÚBLICA}

A esta cuestión se dedica el Criterio CI/008/2015. El derecho de los ciudadanos a acceder a la información pública, previsto en el art. 105, letra c), de la Constitución, se rige, primeramente por ésta y, en segundo lugar, por "la Ley de transparencia, acceso a la información pública y buen gobierno y demás leyes que resulten de aplicación". De este modo la LETAI se configura en nuestro sistema jurídico como la norma básica en materia de acceso a la información. El carácter de ley básica de la LETAI en esta materia tiene como consecuencia principal que las excepciones a su aplicación en materia de acceso a la información pública deben venir expresamente previstas y autorizadas por ella. De este modo, las únicas excepciones a la aplicación directa de las normas de la LETAI sobre acceso a la información son las previstas en su disposición adicional primera ${ }^{39}$.

\footnotetext{
38 Asunto resulto a favor del ciudadano y de los planteamiento suscritos por el Consejo de Transparencia frente a RTVE tras Sentencia no 60/2016 del Juzgado Central contencioso-administrativo no 9 y Sentencia en apelación no 63/2016 de la Sala de lo contencioso-administrativo sección 7 a de la Audiencia Nacional.

39 R/0165/2016. D.A. 1a.1. Estimada por motivos formales. Acceso a los méritos generales y específicos de todos los candidatos presentados a un concurso de traslado. R/0362/2016. D..A. 1a.1. Estimada. Acceso al archivo de la Capitanía Marítima de Las Palmas.
} 
La disposición adicional primera de la LETAI vincula la aplicación supletoria de la ley a la existencia de una norma específica que prevea y regule un régimen de acceso a la información, también específico. En consecuencia, sólo en el caso de que una norma concreta establezca un régimen específico de acceso a la información pública en una determinada materia o área de actuación administrativa, puede entenderse que las normas de la LETAI no son de aplicación directa y operan como normas supletorias. En opinión del Consejo, la mencionada disposición adicional tiene como objetivo la preservación de otros regímenes de acceso a la información que hayan sido o puedan ser aprobados y que tengan en cuenta las características de la información que se solicita, delimite los legitimados a acceder a la misma, prevea condiciones de acceso etc. Por ello, sólo cuando la norma en cuestión contenga una regulación específica del acceso a la información, por más que regule exhaustivamente otros trámites o aspectos del procedimiento, podrá considerarse a la LETAI como supletoria en todo lo relacionado con dicho acceso.

La excepción prevista en la LETAI no realiza una enumeración taxativa de los procedimientos o áreas de actuación que cuentan con regímenes específicos. Los regímenes mencionados en el apartado tres de su disposición adicional primera -el régimen específico de acceso a la legislación medioambiental, contenido en la Ley 27/2006, de 18 de julio, y el previsto en la Ley $37 / 2007$, de 16 de noviembre, sobre reutilización de la información del sector público- lo son a título de ejemplo y admiten la consideración de otros sectores, entre ellos estaría el contenido en los arts. 23 a 32 del Real Decreto 1708/2011, de 18 de noviembre, que establece el sistema de Archivos de la Administración General del Estado o las disposiciones que, en concreta normativa específica, prevean la reserva en el acceso cuando se den determinados condicionantes (secretos oficiales, secreto estadístico) y algunos otros.

La aplicación de la Disposición adicional primera, párrafo 2, de la LETAI, de 9 de diciembre, de transparencia, acceso a la información pública y buen gobierno, requiere la existencia de una norma que prevea una regulación propia del acceso a la información; la legislación incluida en la Ley 19/2013, por su carácter básico, es aplicable a la totalidad de disposiciones que vinculan a los sujetos obligados, supletoriamente en caso de regulación específica del derecho de acceso ${ }^{40}$.

\section{EL CRITERIO CI/009/2015}

Actuación del órgano o unidad competente cuando, en ejercicio del derecho de acceso a la información, se solicite por los interesados información ya objeto de publicidad activa por el organismo de que se trate $^{41}$. El Consejo de Transparencia concluye que de acuerdo con la LETAI, y teniendo especialmente en cuenta el art. 1, el art. 10.2 y la

\footnotetext{
${ }^{40}$ R/0513/2016. D.A. $1^{a} .2$ régimen de acceso específico. Estimada. Información sobre el proceso de toma de datos de un detenido en la vía pública.

$41 \mathrm{R} / 0389 / 2016$. No es información pública. Desestimada. Acceso a su expediente de jubilación.
} 
propia estructura sistemática de la norma, la publicidad activa y el derecho a la información son dos caras distintas de una misma realidad: la transparencia de la actividad pública. En ambos casos la finalidad de la transparencia es garantizar que los ciudadanos conozcan la organización y el funcionamiento de sus instituciones públicas. En este sentido, la publicidad activa ha de entenderse como un elemento facilitador de este conocimiento. A través de ella, las organizaciones y Administraciones públicas sitúan de oficio en régimen de publicidad una serie de datos e informaciones que se entienden de interés general, de manera que puedan ser consultadas por aquellos que lo deseen sin necesidad de hacer una petición expresa. El criterio esgrimido por el Consejo de Transparencia determina que la publicidad activa es una obligación establecida en la LETAI que afecta a la Administración y al resto de sujetos incluidos en el ámbito de aplicación de la ley. El hecho de que una información solicitada por cualquier persona se encuentre en publicidad activa, no exime de la obligación de dar una respuesta concreta en los plazos y condiciones que señale la ley. En caso de que el sujeto que realiza la solicitud haya manifestado expresamente su voluntad de relacionarse de forma no electrónica con la Administración, la información se habrá de servir íntegramente por el medio escogido en la solicitud de información, sin remisión a ninguna plataforma o dirección genérica ni previa colgada en la red. Si no ha optado por ningún sistema específico de relación con la Administración o ha optado por relacionarse por medios electrónicos, sería de aplicación el art. 22.3 y se procedería a la indicación del lugar web donde la información se encuentra en publicidad activa. En ningún caso será suficiente únicamente la remisión genérica al portal o a la sede o página web correspondiente. Es necesario de que se concrete la respuesta. Si por sus características -especialmente de complejidad o volumen-, la información fuera difícilmente suministrable en un soporte no electrónico, la Administración contactará con el solicitante para, bien mediante concreción de los datos, bien mediante comparecencia, bien por su aceptación de un sistema o soporte electrónico ( $C D$, remisión a un correo, etc.) pudiera ver satisfecho su derecho.

\section{LA DESESTIMACIÓN DE UNA SOLICITUD DE ACCESO A LA INFORMACIÓN POR SILENCIO}

La referencia en este caso es el Criterio CI/001/2016. La reclamación presentada ante el Consejo; según se desprende del art. 23.1 de la LETAI, tiene la consideración de "sustitutiva de los recursos administrativos"42. El Tribunal Constitucional ha fijado una reiterada jurisprudencia -entre otras, SSTC 6/1986, de 21 de enero, 204/1987, de 21 de diciembre, 188/2003, de 27 de octubre, 220/2003, de 15 de diciembre, 14/2006, de 16 de

42 R/0016/2017. Silencio. Estimada. Tasación de bienes rústicos por Ingenieros de Caminos.

R/0044/2017. Silencio. Estimada. Copia de expediente sancionador abierto al Banco Popular Español.

R/0286/2015. Silencio. Estimada. Informe sobre vigilancia radiológica del Río Ebro. Central Nuclear Garoña. 
enero, 39/2006, de 13 de febrero, 186/2006, de 19 de junio, 27/2007, de 12 de febrero, y 64/2007, de 27 de marzo-, asumida también por el Tribunal Supremo, según la cual resulta contrario al derecho a la tutela judicial efectiva la posibilidad de que una desestimación presunta adquiera firmeza. Esta doctrina se encuentra sistematizada en el Fundamento Jurídico 3 de la STC 3/2008, de 21 de enero. Además, de acuerdo con reiterada doctrina jurisprudencial y con las previsiones normativas contenidas en los arts. 122 y 124 de la Ley 39/2015 del Procedimiento Administrativo Común de las Administraciones Públicas relativas a la interposición de recurso de alzada y reposición, respectivamente, respecto de resoluciones presuntas, la presentación de una reclamación ante el Consejo de Transparencia y Buen Gobierno frente a la desestimación de una solicitud de acceso a la información por silencio no estará sujeta a plazo.

\section{CONCLUSIÓN}

Los criterios que establece el Consejo de Transparencia y Buen Gobierno en términos generales han de entenderse como las bases que fija la institución para la interpretación de los distintos asuntos que se le plantean a la vez que persiguen que el intérprete de los mismos no sólo preste su atención, sino que también le puedan resultar clarificadores del sentido de la norma desde una perspectiva especializada y con vocación de ser aplicados al caso concreto.

\section{BIBLIOGRAFÍA}

CAMPOS ACUÑA, C., El Consultor de los Ayuntamientos, núm. 24, Sección Zona Local / Observatorio de Transparencia, Quincena del 30 de diciembre de 2015 al 14 de enero de 2016.

FERNÁNDEZ RODRÍGUEZ, J. J., "La transparencia pública como exigencia democrática", Advocatus, núm. 29, 2013, pp. 21-26.

FERNÁNDEZ RODRÍGUEZ, J. J y NEIRA BARRAL, D., "El papel de las defensorías del pueblo en España en el control de la transparencia y el acceso a la información", Revista Estado, Gobierno y Gestión Pública, Universidad de Chile, núm. 27, 2016, pp. 89-116.

GUICHOT REINA, E. (coord.), Transparencia, acceso a la información pública y buen gobierno, Tecnos, Madrid, 2014. 